\title{
Study Accrual Threshold Percent
}

National Cancer Institute

\section{Source}

National Cancer Institute. Study Accrual Threshold Percent. NCI Thesaurus. Code C93677.

An integer specifying a percentage of target accrual for a study. 